\title{
Stratified Assessment and Warning Regimen for Comprehensive Risk Management and Improved lodinated Contrast Media Safety
}

Xue Li

Department of Radiology, Daping Hospital, Army Medical University, Chongqing

Heng Liu

Department of Radiology, PLA Rocket Force Characteristic Medical Center, Beijing

Haiyan Qiu

Department of Radiology, Daping Hospital, Army Medical University, Chongqing

\section{Lingru Wang}

Department of Radiology, Daping Hospital, Army Medical University

Junling Liu

Department of Radiology, Daping Hospital, Army Medical University, Chongqing

\section{Li Zhao}

Department of Radiology, Daping Hospital, Army Medical University, Chongqing

\section{Yaling Wang}

Department of Nursing, Daping Hospital, Army Medical University, Chongqing

Weiguo Zhang ( $\nabla$ Wgzhang01@163.com )

Army Medical University https://orcid.org/0000-0003-2622-3686

\section{Research}

Keywords: risk factor, risk assessment, risk management, iodinated contrast media, adverse drug reaction

Posted Date: July 15th, 2021

DOI: https://doi.org/10.21203/rs.3.rs-711771/v1

License: (1) (1) This work is licensed under a Creative Commons Attribution 4.0 International License.

Read Full License 


\section{Abstract}

Objectives: To determine the relationship between stratified assessment and warning (SAW) regimen for risk factors to iodinated contrast media (ICM) and adverse drug reactions (ADR) occurrence.

Methods: This retrospective study included patients who underwent enhanced CT examinations in our hospital between January 2014 and March 2016 (conventional assessment group) and between April 2017 and December 2019 (SAW group). Initial risk assessment was performed by clinicians when ordering examinations in both periods. The risk re-assessment was performed by simple question-andanswer onsite just before examination in the conventional assessment period, according to the risk factors that deserve special attention in ICM guidelines. In the SAW period, the re-assessment process prior to examination was moved forward as early as possible post-appointment, and a whole-process comprehensive management integrating risk identification, stratification, early warning and prevention was performed according different risk levels. Chi-square test was performed for comparisons of rates.

Results: A total of 120822 cases in the conventional assessment group and 150343 cases in the SAW group were enrolled. The total ADR incidence in the SAW period $(414 / 150343,0.275 \%)$ was lower than that in the conventional assessment period (506/120822, 0.419\%, $\mathrm{P}<0.001)$, in which the proportion of patients who developed ADR decreased by about $34 \%$. It mainly presented as decrease in mild/moderate reactions $(P<0.001)$ and increase in the proportion of mild ADR patients $(P=0.001)$ in the SAW period. Subgroup analysis showed lower mild/moderate ADR incidence in patients with different risk levels and with different ICM injection parameters $(P<0.05)$ following SAW regimen.

Conclusions: SAW regimen was associated with lower mild/moderate ADR incidence and alleviated ADR severity in at-risk patients, which held potential for improved risk management and ICM safety.

\section{Introduction}

lodinated contrast media (ICM) assisted enhanced CT examinations are widely and daily conducted for diagnostic procedures in imaging departments worldwide. Although patients can benefit from their use, ICM possess inherent risk to cause adverse reactions (ADR), with an incidence ranging from $0.2-3.13 \%$ [1-9]. The clinical manifestations vary from mild unspecific physiological disturbances to rare severe and potentially life-threatening events $[1,10]$. The likelihood of ICM-ADR is related to the complicated and combined effects of miscellaneous risk factors, and the occurrence of events follows sporadic and unpredictable pattern. In clinical practice in China, initial risk assessment is usually performed by clinicians at the time of ordering examinations. Due to the limitations of expertise field and knowledge background, clinicians have limited awareness of ICM risk factors, which may lead to inaccurate assessment results. The risk re-assessment needs to be performed by radiology nurses in the form of simple question-and-answer (yes or no) onsite just before examination, according to the risk factors that deserve special attention outlined in international ICM usage guidelines [11, 12]. Inquiring about some complex risk factors may be not detailed or in-depth enough attributed to a tight schedule onsite, making 
the accurate recognition and stratified management of risk factors difficult. The lack of objectively and quantitatively standardized assessment programs have led to inconsistent assessment results among different medical staff and medical institutions. Some patients with advanced age and poor selfknowledge ability are unable to communicate accurately and completely describe their medical information. The inaccurate estimation of risk factors may instigate subsequent excessive/insufficient prevention measures, which inevitably led to a series of clinical issues [13]. If high-risk circumstances were recognized when enquiry, no adequate and appropriate preparation could be implemented due to time constraints $[14,15]$. In this scenario, such a patient population had to be rescheduled for elective examinations, giving rise to delayed radiology diagnosis time and a waste of medical personnel resources [16-18]. These issues have drawn increasing attention of the radiology department.

Current ICM guidelines proposed several common types of ICM-ADR risk factors that deserved special attention and highlighted the importance of risk assessment $[2,19]$. Regrettably, there are no standardized procedures and efficient strategies for stratified assessment and management of ICM risk factors. Despite that several studies reported the assessment and management of patients at risk $[1,18$, 20-22], their results differed and have not been generally accepted. It is urgently demanded to establish a scientific, practicable and widely applicable management process for ICM risk factors, which is of clinical importance to reduce the frequency and/or severity of ICM-ADR, and to ensure maximum safety for the patients. From April 2017, our hospital undertook a standardized quality improvement project that involved a stratified assessment and warning (SAW) regimen for ICM risk factors, which focused on issues concerning ICM-ADR that integrated risk identification, stratification, early warning and prevention, and aimed to improve the ICM safety. With the radiology nurses as the main body, through structured cooperation of the radiological team as well as their collaboration with clinical departments, stratified assessment and personalized management of risk factors were implemented during the period from patient appointment to ICM injection. This study aimed to determine the relationship between the SAW regimen and acute and delayed ICM-ADR occurrence.

\section{Materials And Methods}

\section{Study Participants}

CT scan data was collected and retrospectively analyzed from our hospital, a comprehensive tertiary and grade A medical institution with 2,600 beds that provides all medical and surgical services. This retrospective study was approved by the institutional review board of our hospital. The written informed consent was exempted because this study would not affect the rights of the participants, and all personal data were removed and coded as arbitrary numbers. The research flow chart is shown in Fig. 1. Inclusion criteria: (i) Patients who met the indications and underwent routine CT enhancement from January 2014 to March 2016 (conventional assessment period) and from April 2017 to December 2019 (SAW period) $[11,12]$. (ii) Patients who had risk factors outlined in international ICM usage guidelines [11, 12], but needed CT enhancement for disease diagnosis. (iii) There was no age limit for patients. Exclusion criteria: (i) Patients with incomplete form data filling; (ii) Unconscious patients with unavailable assessment; (iii) 
Emergency patients with unknown medical history. We allowed a transition period of 12 months (from April 2016 to March 2017) for quality improvement project to fully permeate the examinations, and data from during this period were not analyzed in this study.

\section{Assessment in the conventional assessment group}

Initial risk assessment was performed by clinicians at the time of ordering examinations. And the risk reassessment was performed on-site just before examination by radiology nurses in the form of simple question-and-answer (yes or no), according to the risk factors that deserve special attention outlined in international ICM guidelines $[11,12]$. The radiology nurses with over 8 years of work experience asked the patients and their families for the patients' medical history, filled out the conventional assessment form (Table S1, Supplemental Materials), informed the risks for ICM injection, and asked the patients to sign the informed consent form for ICM injection. The patients were closely observed during and after examinations, and abnormal reactions were treated in time and routine hydration were performed. For patients with risk factors $[11,12]$, the radiology nurses reported to the radiologists, and the radiologists should communicate with the clinicians about the individualized risk-benefit ratio of examination, countermand the examination directly, reschedule for elective examinations after clinical treatment if necessary, and consider alternative imaging modalities with comparable diagnostic values.

\section{Stratified assessment of risk factors in the SAW group}

Design stratified assessment form: Continuous quality improvement was carried out on the basis of the conventional assessment. The assessment items for risk factors were optimized and updated, and the degrees of risk factors were stratified. (i) Determine the risk assessment items: Through previous observation results of hundreds of thousands of CT-enhanced patients $[9,20,23]$, we concluded that patients with asthma, heart disease, hypertension, ICM-ADR history, other allergy history, tumor chemotherapy, and elder patients presented a higher ADR incidence. To ensure the rationality and effectiveness of the screening process, the items in the assessment form were improved by combining our institutional results, international ICM guidelines and the latest literature. (ii) Determine the contents in the assessment form: An expert seminar was held by five radiologists, five radiology technicians, and five radiology nurses. All of them were senior members of the local Contrast Media Safety Committee with deputy senior professional titles and above, and had worked in tertiary hospitals for more than 8 years. The risk factors were discussed item-by-item and were classified into different risk levels, including high risk, low risk, and no risk (including unknown risk). Ultimately, 12 screening items were determined in the stratified assessment form (Table S2, Supplemental Materials).

Move forward the re-assessment process: The re-assessment process prior to examination was moved forward as early as possible post-appointment. The radiology nurses with over 8 years of work experience filled out the stratified assessment form item-by-item. For patients with unclear information descriptions, their medical histories and related test results were obtained through the medical information system. The assessment of diseases like thyroid diseases, hypertension, heart insufficiency, renal insufficiency, and asthma were based on their final clinical diagnosis. 
ADR record cards and risk warning signboards: (i) ADR record card: The card recorded the date and time for previous ADR, culprit ICM brands, injection dosages and speeds, clinical symptoms, severities, treatment and outcomes. The card could accurately reflect the events that occurred, and was held by the patients themselves and brought to any other hospital for check-up before examination. (ii) Risk warning label: The risk degrees were divided into high-risk, low-risk and no-risk, and the high-risk and low-risk was colored in red and yellow respectively. For patients with multiple risk factors, the most serious risk factor was adopted as the basis for determining the risk degree. The patients' risk levels were carefully determined by one doctor-in-charge and one nurse-in-charge both with over 8 years of work experience. If disagreements occurred, they discussed with clinicians to determine the final assessment results.

\section{Determine intervention strategies in the SAW group}

According to different risk stratification, corresponding comprehensive intervention was implemented (Table S3, Supplemental Materials): (i) Clinical communication: For high-risk patients, the radiology nurses reported to the radiologists, and the radiologists fully communicated with the clinicians to evaluate the risk-benefit ratio for examination and determined whether the patients would receive ICM. For patients with histories of severe ICM-ADR, unstable asthma, and severe cardiovascular diseases, preventive treatments were carried out by clinicians and the examination time was reasonably rescheduled. (ii) Patient communication: The radiology nurses informed the patients about the assessment decisions and explained the precautions during examination. Ordinary patients signed a general informed consent form. Patients with risk factors signed an informed consent form with caution, which emphasized more on the possible adverse consequences post examinations for high-risk patients. (iii) Full predictive process: For patients with risk factors but need examination for disease diagnosis, the radiology nurses first evaluated the efficacy of pretreatment after the patients arrived at the radiology department during the post-appointment period, and prepared contingency plans for different risk factors. Different risk signs were labeled on the checklists to remind technicians of formulating personalized examination programs, including adopting lower injection dosages and rates of ICM, switching to another class of ICM for patients with ICM-ADR histories, performing dynamic electrocardiograph monitoring during the examination, closely observing the condition changes, asking whether the patients had abnormal reactions. High-risk patients were followed up after examination by dedicated staff. If any abnormality occurred, the emergency department or residents were informed to immediately start the rescue emergency plan, and follow up was well-performed.

\section{Data documentation and quality control}

Detail comparisons of conventional assessment and SAW regimen are shown in Table 1. All patients who underwent enhanced CT examination routinely filled out the conventional assessment form or the updated stratified assessment form for risk factors (Table S2, Supplemental Materials), and all patients who developed ADR filled out the uniform ADR record form (Table S4, Supplemental Materials). Acute and delayed reactions (within one week of ICM injection) were observed and recorded by radiology nurses. The assessment form mainly included basic information of patients, risk factors, examination 
sites, ICM names, injection dosages and injection speeds. For patients who developed ADR, the dates of occurrence, time of occurrence, severities, ICM names, clinical manifestations, vital signs, treatment measures, drugs used, remission time, and clinical outcomes were recorded. The ADR severities (mild, moderate, severe) were determined according to ACR Manual on Contrast Media (Version 10.3)[2]. Considering some patients may develop allergic-like reactions and chemotoxic reactions simultaneously, and some symptoms were equivocal and hard to be differentiated, these two subtypes of ADR were collectively defined as adverse events. Thyroid toxicity and post-contrast acute kidney injury were not follow-up observed. 
Table 1

Summary of conventional assessment and SAW regimen

Conventional assessment period

Data collection Retrospectiv

Identification of ACR and ESUR guidelines risk factors

ADR

Acute and delayed reactions

observation

types

Who diagnoses Radiologists

ADR

Identification of

ACR and ESUR guidelines

ADR severities

ADR record

form

Yes (Table S4)

Yes (Table S4)

Same

Initial risk

assessment

By clinicians when ordering examinations

Risk reassessment staff

Risk reassessment

time

Risk reassessment

form

Informed

consent

All patients signed a genera informed consent form

SAW period

Retrospective

Same

ACR and ESUR guidelines

Same

Acute and delayed reactions

Same

Radiologists

Same

ACR and ESUR guidelines

Same

By radiology nurses with over

8 years of work experience

Just before examination

Conventional assessment

form (Table S1)

By clinicians when ordering

Same examinations

By radiology nurses with over 8

Same years of work experience

As early as possible post-

Different appointment

Stratified assessment form (Table

Different $\mathrm{S} 2)$

Ordinary patients signed a general

Different

informed consent form. Patients

with risk factors signed an informed

consent form with caution.

Risk levels No stratification

Stratification: high risk, low risk, and

Different no risk (including unknown risk)

Clinical

communication

Just before

examination,countermand

the examination directly or

reschedule for elective

examinations

Inform the risk levels in advance, remind the clinic for specific interventions to ensure appropriate and adequate preparation prior to examination

Yes

Same

Hydration

Yes

Patients with histories of severe ICM-

Patients with histories of

Preventive ICM-ADR and other allergies

Different

treatments
ADR, unstable asthma, and severe cardiovascular diseases 


\begin{tabular}{|llll|}
\hline & $\begin{array}{l}\text { Conventional assessment } \\
\text { period }\end{array}$ & SAW period & Notes \\
\hline $\begin{array}{l}\text { Switch to } \\
\text { another non- } \\
\text { culprit ICM }\end{array}$ & No & Yes & Different \\
$\begin{array}{l}\text { ADR record } \\
\text { card }\end{array}$ & No & Yes & Different \\
$\begin{array}{l}\text { Risk warning } \\
\text { label }\end{array}$ & No & Yes & Different \\
\hline $\begin{array}{l}\text { Personalized } \\
\text { examination } \\
\text { programs for } \\
\text { high-risk } \\
\text { patients }\end{array}$ & No & Yes & Different \\
\hline $\begin{array}{l}\text { Observation } \\
\text { after } \\
\text { examination }\end{array}$ & $\begin{array}{l}\text { All patients were routinely } \\
\text { followed up after } \\
\text { examination }\end{array}$ & $\begin{array}{l}\text { High-risk patients were followed up } \\
\text { after examination by dedicated staff. }\end{array}$ & Different \\
\hline
\end{tabular}

Abbreviations: SAW, stratified assessment and warning; ACR, American College of Radiology; ESUR, European Society of Genitourinary Radiology; ADR, adverse drug reactions; ICM, iodinated contrast media

To ensure the accuracy and consistency of the assessment results, the radiologists, technicians, and nurses received formal trainings in advance, such as thematic lectures, on-site demonstrations, and situational presentations. The training contents include ICM-related risk factors and intervention methods, assessment form usages, clinical information acquirements, informed consents, and how to implement emergency treatments. The evaluation was conducted by dedicated staff, and the data was collected with unified standards and checked daily, and the missing items were completed in time. After data registration, two medical staff with over 8 years of work experience checked the original data blind-toblind to ensure the data accuracy and completeness.

\section{Statistical analysis}

All variables were descriptively analyzed. Continuous variables were described in terms of mean values and standard deviation. The counting data was presented in terms of frequencies and percentages (\%). Chi-square test was performed for rates comparison on SPSS 22.0 (IBM, Chicago, USA), and P< 0.05 was considered statistically significant. The rate differences and $95 \%$ confidence interval $(\mathrm{Cl})$ were estimated using VassarStats website http://vassarstats.net/index.html.

\section{Results}

A total of 273437 cases underwent enhanced CT examinations between January 2014 and December 2019, in which "case" was equal to the number of ICM administration. 2272 participants were excluded (Fig. 1), including 722 patients with incomplete form data filling, 643 unconscious patients with unavailable assessment, and 907 emergency patients with unknown medical history. After excluding 
participants with incomplete follow-up, the complete case analysis consisted of data from 120822 eligible cases in the conventional assessment group (0-104 years old, $58 \pm 15$ years, 66573 men [55\%]) and 150343 eligible cases (0-102 years old, $58 \pm 14$ years, 83937 men [56\%]) in the SAW group (Fig. 1). Demographic and baseline characteristics of study participants are summarized in Table 2.

Table 2

Summary of participant characteristics

\begin{tabular}{|c|c|c|c|}
\hline & Characteristics & $\begin{array}{l}\text { Conventional assessment group } \\
\text { (\%) }\end{array}$ & SAW group (\%) \\
\hline No. of patients & & 120822 & 150343 \\
\hline \multirow[t]{2}{*}{ Gender } & Male & 66753(55.249) & $83,937(55.830)$ \\
\hline & Female & $54069(44.751)$ & $66406(44.170)$ \\
\hline \multirow[t]{5}{*}{ Age (years) } & Age range (years) & $0-104$ & $0-102$ \\
\hline & Mean age (years) & $58 \pm 15$ & $58 \pm 14$ \\
\hline & $0-29$ & $5013(4.149)$ & 5592(3.719) \\
\hline & $30-69$ & $89741(74.275)$ & 111922(74.444) \\
\hline & $\geq 70$ & 26068(21.576) & $32829(21.836)$ \\
\hline \multirow{3}{*}{$\begin{array}{l}\text { Examination } \\
\text { region }\end{array}$} & Coronary CTA & 23718(17.707) & 26869(16.622) \\
\hline & $\begin{array}{l}\text { Head and neck } \\
\text { CTA/CTP }\end{array}$ & 40836(30.487) & $40741(25.203)$ \\
\hline & Other regions & 69392(51.806) & $94039(58.175)$ \\
\hline \multirow[t]{2}{*}{ Types of ICM } & Hypotonic & 102208(84.594) & 132906(88.402) \\
\hline & Isotonic & 18614(15.406) & 17437(11.598) \\
\hline \multirow[t]{3}{*}{ Injection dose } & $<100 \mathrm{~mL}$ & 104971(86.881) & 138702(92.257) \\
\hline & $\geq 100 \mathrm{~mL}$ & 12264(10.150) & 11596(7.713) \\
\hline & Unknown & $3587(2.969)$ & $45(0.030)$ \\
\hline \multirow[t]{3}{*}{ Injection speed } & $<5 \mathrm{~mL} / \mathrm{s}$ & $70835(58.628)$ & $97967(65.162)$ \\
\hline & $\geq 5 \mathrm{~mL} / \mathrm{s}$ & 42878(35.489) & 52332(34.808) \\
\hline & Unknown & 7109 (5.884) & $44(0.029)$ \\
\hline
\end{tabular}

Abbreviations: ICM, iodinated contrast media; ADR, adverse drug reactions; SAW, stratified assessment and warning; CTA, CT angiography; CTP, CT perfusion

Note: More than one examination regions might be involved in one enhanced CT examination. 
Comparison of the incidence and proportions of ADR with different severities are shown in Fig. 2. The total ADR incidence in the SAW group (414 of 150343 examinations, $0.275 \%$ ) was lower than that in the conventional assessment group (506 of 120822 examinations, $0.419 \%, \mathrm{P}<0.001$ ), and the proportion of patients who developed ADR decreased by about $34 \%$. No statistical difference was found in the severe ADR incidence $(P=0.33)$. The ADR incidence in patients with risk factors is shown in Table 3 . Whether patients with no risk or at risk, high-risk or low-risk, single-risk-factor or multi-risk-factor, the SAW group exhibited a lower ADR incidence than that in the conventional assessment group $(P<0.05)$. The rate difference in high-risk patients $(0.515 \%, 95 \% \mathrm{Cl}: 0.262 \%, 0.768 \%)$ was greater than that in low-risk patients $(0.124 \%, 95 \% \mathrm{Cl}: 0.005 \%, 0.244 \%)$, and the proportion of ADR in high-risk patients was reduced by about $58 \%$. Comparison of the ADR incidence in patients with different single risk factors are shown in Fig. 3. The ADR incidence in patients with ICM-ADR history, heart disease, hypertension, and advanced age ( $\geq 70$ years) in the SAW group was lower than that in the conventional assessment group respectively $(P<0.05)$. The proportion of these populations who developed ADR was reduced by about $52 \%, 60 \%, 56 \%$, and $41 \%$, respectively. 40 patients who developed ADR in the conventional assessment period and subsequently received ICM again during the SAW period were analyzed (data not shown), and none of them developed recurrent events. The records showed that another non-culprit ICM was used for every patient and no prophylactic medication was performed in these patients. The ADR incidence in patients with different ICM injection parameters are shown in Table 4. Whether isotonic or hypotonic ICM, the SAW group exhibited a lower ADR incidence than that in the conventional assessment group $(\mathrm{P}<$ $0.01)$, which was mainly reflected in mild and moderate ADR $(P<0.05)$. Whether low or high injection dosages and speeds, the ADR incidence in the SAW group was lower than that in the conventional assessment group $(P<0.05)$. 
Table 3

The ADR incidence in patients with risk factors

\begin{tabular}{|c|c|c|c|c|c|}
\hline & & $\begin{array}{l}\text { Conventional } \\
\text { assessment group } \\
\text { (\%) }\end{array}$ & SAW group (\%) & $\begin{array}{l}P \\
\text { value }\end{array}$ & $\mathrm{RD}(95 \% \mathrm{Cl})$ \\
\hline \multirow[t]{3}{*}{$\begin{array}{l}\text { With/without } \\
\text { risk factors }\end{array}$} & No risk & $0.382(372 / 97439)$ & $0.252(274 / 108786)$ & $\begin{array}{l}< \\
0.001\end{array}$ & $\begin{array}{l}0.130(0.081 \\
0.179)\end{array}$ \\
\hline & At risk & $0.573(134 / 23383)$ & $0.337(140 / 41557)$ & $\hat{0}_{0.001}$ & $\begin{array}{l}0.236(0.125 \\
0.348)\end{array}$ \\
\hline & $P$ value & $<0.001$ & 0.01 & & \\
\hline \multirow[t]{3}{*}{$\begin{array}{l}\text { Patients with } \\
\text { no risk }\end{array}$} & Mild ADR & $0.348(339 / 97439)$ & $0.243(264 / 108786)$ & $<.001$ & $\begin{array}{l}0.105(0.058 \\
0.152)\end{array}$ \\
\hline & $\begin{array}{l}\text { Moderate } \\
\text { ADR }\end{array}$ & $0.030(29 / 97439)$ & 0.007(8/108786) & $<.001$ & $\begin{array}{l}0.022(0.010 \\
0.034)\end{array}$ \\
\hline & $\begin{array}{l}\text { Severe } \\
\text { ADR }\end{array}$ & $0.004(4 / 97439)$ & $0.002(2 / 108786)$ & 0.43 & $\begin{array}{l}0.002(-0.003 \\
0.007)\end{array}$ \\
\hline \multirow[t]{3}{*}{$\begin{array}{l}\text { Patients at } \\
\text { risk }\end{array}$} & Mild ADR & $0.517(121 / 23383)$ & $0.325(135 / 41557)$ & $<.001$ & $\begin{array}{l}0.192(0.09, \\
0.30)\end{array}$ \\
\hline & $\begin{array}{l}\text { Moderate } \\
\text { ADR }\end{array}$ & $0.043(10 / 23383)$ & $0.007(3 / 41557)$ & 0.01 & $\begin{array}{l}0.036(0.01 \\
0.07)\end{array}$ \\
\hline & $\begin{array}{l}\text { Severe } \\
\text { ADR }\end{array}$ & $0.013(3 / 23383)$ & $0.005(2 / 41557)$ & 0.36 & $\begin{array}{l}0.008(-0.01 \\
0.03)\end{array}$ \\
\hline \multirow[t]{3}{*}{ Risk level } & Low risk & $0.448(75 / 16746)$ & $0.324(99 / 30583)$ & 0.03 & $\begin{array}{l}0.124(0.005 \\
0.244)\end{array}$ \\
\hline & High risk & $0.889(59 / 6637)$ & $0.374(41 / 10974)$ & $<.001$ & $\begin{array}{l}0.515(0.262 \\
0.768)\end{array}$ \\
\hline & $P$ value & $<0.001$ & 0.44 & & \\
\hline \multirow[t]{2}{*}{$\begin{array}{l}\text { Number of risk } \\
\text { factors }\end{array}$} & $\begin{array}{l}\text { Single } \\
\text { risk }\end{array}$ & $0.550(116 / 21074)$ & $0.324(117 / 36135)$ & $\begin{array}{l}< \\
0.001\end{array}$ & $\begin{array}{l}0.227(0.111 \\
0.343)\end{array}$ \\
\hline & Multi-risk & $0.780(18 / 2309)$ & $0.424(23 / 5422)$ & 0.049 & $\begin{array}{l}0.355(-0.043 \\
0.754)\end{array}$ \\
\hline
\end{tabular}

Abbreviations: ADR, adverse drug reactions; SAW, stratified assessment and warning; RD, rate difference; $\mathrm{Cl}$, confidence interval 
Table 4

The ADR incidence in patients with different ICM injection parameters

\begin{tabular}{|c|c|c|c|c|c|}
\hline & & $\begin{array}{l}\text { Conventional } \\
\text { assessment group (\%) }\end{array}$ & SAW group (\%) & $\begin{array}{l}P \\
\text { value }\end{array}$ & $\mathrm{RD}(95 \% \mathrm{Cl})$ \\
\hline \multirow[t]{3}{*}{$\begin{array}{l}\text { Types of } \\
\text { ICM }\end{array}$} & Isotonic & $0.693(129 / 18614)$ & $0.470(82 / 17437)$ & 0.01 & $\begin{array}{l}0.223(0.066 \\
0.379)\end{array}$ \\
\hline & Hypotonic & $0.369(377 / 102208)$ & $0.250(332 / 132906)$ & $<.001$ & $\begin{array}{l}0.119(0.073, \\
0.165)\end{array}$ \\
\hline & $P$ value & $<0.001$ & $<0.001$ & & \\
\hline \multirow[t]{3}{*}{$\begin{array}{l}\text { Isotonic } \\
\text { ICM }\end{array}$} & Mild ADR & $0.629(117 / 18614)$ & 0.458(80/17437) & 0.03 & $\begin{array}{l}0.171(0.018, \\
0.321)\end{array}$ \\
\hline & $\begin{array}{l}\text { Moderate } \\
\text { ADR }\end{array}$ & $0.059(11 / 18614)$ & $0.005(1 / 17437)$ & 0.01 & $\begin{array}{l}0.054(0.02 \\
0.1)\end{array}$ \\
\hline & $\begin{array}{l}\text { Severe } \\
\text { ADR }\end{array}$ & $0.005(1 / 18614)$ & $0.005(1 / 17437)$ & 1.00 & $\begin{array}{l}0(-0.03 \\
0.03)\end{array}$ \\
\hline \multirow[t]{3}{*}{$\begin{array}{l}\text { Hypotonic } \\
\text { ICM }\end{array}$} & Mild ADR & $0.336(343 / 102208)$ & $0.240(319 / 132906)$ & $<.001$ & $\begin{array}{l}0.096(0.051 \\
0.140)\end{array}$ \\
\hline & $\begin{array}{l}\text { Moderate } \\
\text { ADR }\end{array}$ & $0.027(28 / 102208)$ & $0.008(10 / 132906)$ & $\dot{0} 001$ & $\begin{array}{l}0.019(0.01 \\
0.03)\end{array}$ \\
\hline & $\begin{array}{l}\text { Severe } \\
\text { ADR }\end{array}$ & $0.006(6 / 102208)$ & $0.002(3 / 132906)$ & 0.29 & $\begin{array}{l}0.004(0 \\
0.01)\end{array}$ \\
\hline \multirow[t]{3}{*}{$\begin{array}{l}\text { Injection } \\
\text { dose }\end{array}$} & $<100 \mathrm{~mL}$ & $0.393(413 / 104971)$ & $0.278(385 / 138702)$ & $<.001$ & $\begin{array}{l}0.115(0.07 \\
0.16)\end{array}$ \\
\hline & $\geq 100 \mathrm{~mL}$ & $0.595(73 / 12264)$ & $0.250(29 / 11596)$ & $\dot{0} 001$ & $\begin{array}{l}0.345(0.18 \\
0.52)\end{array}$ \\
\hline & $P$ value & 0.01 & 0.59 & & \\
\hline \multirow[t]{3}{*}{$\begin{array}{l}\text { Injection } \\
\text { speed }\end{array}$} & $<5 \mathrm{~mL} / \mathrm{s}$ & $0.336(238 / 70835)$ & $0.267(262 / 97967)$ & 0.01 & $\begin{array}{l}0.069(0.02 \\
0.12)\end{array}$ \\
\hline & $\geq 5 \mathrm{~mL} / \mathrm{s}$ & $0.571(245 / 42878)$ & $0.290(152 / 52332)$ & $<.001$ & $\begin{array}{l}0.281(0.20 \\
0.37)\end{array}$ \\
\hline & $P$ value & $<0.001$ & 0.42 & & \\
\hline
\end{tabular}

Abbreviations: ICM, iodinated contrast media; ADR, adverse drug reactions; SAW, stratified assessment and warning; $\mathrm{RD}$, rate difference; $\mathrm{Cl}$, confidence interval

\section{Discussion}

Current ICM guidelines lack large-scale data base for optimal management of risk factors and effective prevention of ICM-ADR $[24,25]$. Standardized SAW regimen can standardize the roles and behaviors of medical staff in the radiological team. This may contribute to accurate recognition and stratified 
management of risk factors, which is of great significance for improving the ICM safety. As a quality improvement project in a large clinical cohort (271165 cases), our study determined the relationship between standardized SAW scheme and ADR occurrence. The total ADR incidence in the SAW group was lower than that in the control group $(0.275 \%$ vs $0.419 \%, P<0.001)$, with a rate difference of $0.144 \%$ (95\% Cl: $0.10 \%, 0.19 \%)$. The decrease in ADR occurrence mainly presented as a decrease in mild $(P<0.001)$ and moderate reactions $(P<0.001)$, and an increase in the proportion of mild ADR patients $(P=0.001)$.

\section{The relationship between SAW regimen and reduced ADR occurrence}

Given the critical role of ICM in modern medical imaging and the huge population for enhanced CT examinations worldwide, substantial reduction in the potential risks of ICM administration is of great significance to alleviating the social, medical and economic burden [14, 15]. The decreased ADR occurrence in the SAW period mainly presented as a higher proportion of mild ADR and a lower proportion of moderate ADR. This is of great importance for alleviating the rescue and disposal loads of medical personnel. Attributed to the extremely low incidence of severe life-threatening anaphylaxis, the Chi-square test result was unreliable due to the very small size of positive events. The relationship between SAW scheme and severe ADR requires larger sample size for verification. To investigate relationship between SAW regimen and patient subgroups, patients were divided into no-risk (including unknown-risk) and atrisk based on the assessment results. The greater rate difference of ADR in at-risk patients suggested that the SAW regimen had a more direct and remarkable effect on this population. The effect of SAW scheme on patients with no-risk and at-risk were mainly manifested as decreases in mild and moderate ADR. Further analysis revealed that the ADR incidence in patients with whether high-risk or low-risk, single-riskfactor or multi-risk-factor in the SAW period was lower than the conventional assessment period, respectively. The greater rate difference in high-risk patients suggested that SAW regimen had a more direct and remarkable effect on this population.

The ADR occurrence in patients with various single risk factors was further analyzed. The results showed that patients with ICM-ADR history, heart disease, hypertension, and advanced age ( $\geq 70$ years) in the SAW group had a lower ADR incidence than that in the conventional assessment group respectively $(\mathrm{P}<$ 0.05). The proportion of these populations who developed ADR was reduced by about $52 \%, 60 \%, 56 \%$, and $41 \%$, respectively. As the possible interference caused by the different basic physical conditions among different patients was eliminated, the aforementioned self-control study results from 40 patients with ICM-ADR history strongly indicated that SAW program was remarkably associated with prevention and control of ADR reoccurrence. While no statistical difference $(P>0.05)$, the ADR incidence in patients with history of other allergies or cancer was lower. This indicated that some treatment measures (e.g., replacing the culprit ICM, controlling the injection dosages and speeds) might have a certain effect on inhibiting ADR occurrence, which was consistent with previous reports $[2,3,19,26,27]$.

These effect of ICM injection dosages and speeds on ADR occurrence in the conventional assessment group was consistent with reports in the literature $[28,29]$. Interestingly, there was no statistically significant difference in the ADR incidence in patients with high and low injection dosages in the SAW 
group $(P=0.587)$, but both were lower than those with low injection dosages in the conventional assessment group. This might suggest that following SAW regimen, the ADR incidence in patients with high dosages could be reduced to a level similar to or below that of patients with low dosages in the conventional assessment group. The injection speed data showed similar results. These results further indicated that the SAW regimen had certain directive significance for selecting appropriate ICM parameters. It suggested that if conditions permit in clinical practice, hypotonic ICM could be chosen for replacement for high-risk patients with an isotonic ICM-ADR history, and avoid the injection dose $\geq 100$ $\mathrm{mL}$ and the injection speed $\geq 5 \mathrm{~mL} / \mathrm{s}$ whenever possible.

\section{Reasons for lower ADR occurrence following SAW regimen}

As there were no changes in patient care and quality medical between conventional assessment period and quality improvement period, there was a close relationship between SAW regimen and decreased ADR occurrence. The re-assessment process prior to examination was moved forward as early as possible post-appointment by radiology nurses in the SAW period to guarantee appropriate and adequate preparation of patients prior to examination. Our intervention regimen was not limited to anti-allergy for patients with ICM-ADR histories, it emphasized more on the full cooperation between the radiology department and clinical departments before examination $[9,20,23]$. The purpose was to develop specific treatment plans for patients who needed specific treatments, mainly including adequate fluid intake and treatment measures against high-risk underlying diseases. Furthermore, ADR history record card and risk warning signboards were introduced. Clear and exact ADR documentations could help nurses obtain an appropriate and adequate medical history for the patients, quickly find out the culprit ICM responsible for previous ADR, so that another non-culprit ICM could be recommended in subsequent examination procedures, which is usually tolerated very well by the patients $[26,30]$. The risk warning signs reminded technicians to pay close attention to the patients' condition, and control the injection dosage and speed of ICM for at-risk patients. It also enabled nurses to select appropriate and individual nursing measures according to different risk levels, implement dynamic monitoring during the examination, and observe closely after examination. Taken together, ADR could be timely recognized and treated, and the severe ADR incidence could be minimized in patients at risk. Considering advantages including unified standards, standardized procedures, simple methods, and specific treatment measures, the SAW regimen possessed high clinical practicality and promotion value.

This study has some limitations. First, this study was not a randomized trial and the confounders were not adjusted when making comparisons, which might exist unrecognized changes and unmeasured differences in patient populations. Prospective multi-center randomized controlled trials will help to further validate the clinical efficacy of SAW regimen. Second, the phenomena that abandoned examinations directly, rescheduled for elective examinations, and selected alternative imaging modalities arising from risk overestimation were significantly reduced in the SAW period. However, the exact number of these cases were not documented in details. Furthermore, we focused on the ADR occurrence in patients with different risk levels, but did not further address the relationship between different severities of underlying risk diseases and ADR. Nevertheless, our results showed that following standardized SAW 
regimen, patients at-risk, especially high-risk patients and the ones with multiple risk factors, had a significantly reduced ADR incidence in real-life practice. The cumulative effect of multiple risk factors deserves further verification.

\section{Conclusions}

In conclusion, the whole-process SAW regimen implemented in a large clinical cohort, built a comprehensive risk management process with high clinical practicality, standardized the roles and behaviors of the radiological team in risk screening, guaranteed the accuracy and reliability of risk assessment, and realized timely identification and effective management of risk factors. As a result, SAW regimen was associated with lower mild/moderate ADR incidence and alleviated ADR severity in at-risk patients, which held potential for improved risk management and ICM safety.

\section{List Of Abbreviations}

ICM, iodinated contrast media; ADR, adverse drug reactions; SAW, stratified assessment and warning; $\mathrm{Cl}$, confidence interval

\section{Declarations}

Ethics approval and consent to participate: This retrospective study was approved by the institutional review board of our hospital. The written informed consent was exempted because this study would not affect the rights of the participants, and all personal data were removed and coded as arbitrary numbers.

Consent for publication: Not applicable

Availability of data and materials: The datasets during and/or analysed during the current study available from the corresponding author on reasonable request.

Competing interests: The authors declare no conflict of interest.

Funding sources: This work was supported by the Fund of Chongqing 2019 Science and Technology Joint Medical Research Project (2019ZDXM049) and Chongqing Clinical Research Center for Imaging and Nuclear Medicine (CSTC2015YFPT-gcjsyjzx0175).

Author contributions: X.L. and H.L. contributed equally to this work. Guarantors of integrity of entire study, Y.L.W., W.G.Z.; study concepts/study design, Y.L.W., W.G.Z.; data acquisition or data analysis/interpretation, all authors; manuscript drafting for important intellectual content, X.L. H.L.; approval of final version of submitted manuscript, all authors; agrees to ensure any questions related to the work are appropriately resolved, all authors; literature search, X.L., H.L.; clinical studies, H.Y.Q., L.R.W., L.Z., J.L.L.; statistical analysis, X.L., H.L.; and manuscript editing, Y.L.W., W.G.Z.

Acknowledgements: None. 


\section{References}

1. H.K. Park, M.G. Kang, M.S. Yang, J.W. Jung, S.H. Cho, H.R. Kang, Epidemiology of drug-induced anaphylaxis in a tertiary hospital in Korea, Allergology international : official journal of the Japanese Society of Allergology 66(4) (2017) 557-562.

2. ACR Committee on Drugs and Contrast Media. ACR Manual on Contrast Media. Version 10.3. 2018. Available at: http://www.acr.org/Clinical-Resources/Contrast-Manual.

3. Hypersensitivity Reactions to lodinated Contrast Media: A Multicenter Study of 196081 Patients, Radiology 293(1) (2019) 117-124.

4. H. Katayama, K. Yamaguchi, T. Kozuka, T. Takashima, P. Seez, K. Matsuura, Adverse reactions to ionic and nonionic contrast media. A report from the Japanese Committee on the Safety of Contrast Media, Radiology 175(3) (1990) 621-8.

5. L. Suh-Young, K. Dong Yoon, K. Ju-Young, Y. Soon Ho, C. Young-Hoon, L. Whal, C. Sang Heon, K. HyeRyun, Incidence and risk factors of low-osmolar iodinated contrast media related immediate hypersensitivity reactions: A longitudinal study based on a real-time monitoring system, Journal of investigational allergology \& clinical immunology : official organ of the International Association of Asthmology (INTERASMA) and Sociedad Latinoamericana de Alergia e Inmunologia 29(6) (2019).

6. J. An, H. Jung, O.Y. Kwon, Y. Kang, J.H. Lee, H.K. Won, W.J. Song, H.S. Kwon, Y.S. Cho, H.B. Moon, Differences in adverse reactions among iodinated contrast media: Analysis of the KAERS database, Journal of Allergy \& Clinical Immunology in Practice (2019).

7. M.J. Torres, A. Trautmann, I. Böhm, K. Scherer, A. Barbaud, S. Bavbek, P. Bonadonna, J. Cernadas, A. Chiriac, F. Gaeta, A.M. Gimenez-Arnau, H. Kang, E. Moreno, K. Brockow, Practice Parameters for Diagnosing and Managing lodinated Contrast Media Hypersensitivity, Allergy (2020).

8. C.L. Wang, E.V. Soloff, Contrast Reaction Readiness for Your Department or Facility, Radiologic clinics of North America 58(5) (2020) 841-850.

9. X. Li, H. Liu, L. Zhao, J. Liu, L. Cai, L. Liu, W. Zhang, Clinical observation of adverse drug reactions to non-ionic iodinated contrast media in population with underlying diseases and risk factors, The British journal of radiology 90(1070) (2017) 20160729.

10. S. Han, S.H. Yoon, W. Lee, Y.H. Choi, D.Y. Kang, H.R. Kang, Management of Adverse Reactions to lodinated Contrast Media for Computed Tomography in Korean Referral Hospitals: A Survey Investigation, Korean journal of radiology 20(1) (2019) 148-157.

11. ACR Committee on Drugs and Contrast Media. ACR Manual on Contrast Media, Version 10.2. 2016.

12. European Society of Urogenital Radiology. ESUR Guidelines on Contrast Agents. Version 9.0. 2015.

13. I. Böhm, J. Morelli, K. Nairz, P. Silva Hasembank Keller, J.T. Heverhagen, Myths and misconceptions concerning contrast media-induced anaphylaxis: a narrative review, Postgraduate medicine 129(2) (2017) 259-266.

14. M.S. Davenport, R.H. Cohan, J.H. Ellis, Contrast media controversies in 2015: imaging patients with renal impairment or risk of contrast reaction, AJR. American journal of roentgenology 204(6) (2015) 
1174-81.

15. M.S. Davenport, R.H. Cohan, S. Khalatbari, J.H. Ellis, The challenges in assessing contrast-induced nephropathy: where are we now?, AJR. American journal of roentgenology 202(4) (2014) 784-9.

16. M.S. Davenport, M.A. Perazella, J. Yee, J.R. Dillman, D. Fine, R.J. McDonald, R.A. Rodby, C.L. Wang, J.C. Weinreb, Use of Intravenous lodinated Contrast Media in Patients with Kidney Disease: Consensus Statements from the American College of Radiology and the National Kidney Foundation, Radiology 294(3) (2020) 660-668.

17. R.W. Katzberg, J.H. Newhouse, Intravenous contrast medium-induced nephrotoxicity: is the medical risk really as great as we have come to believe?, Radiology 256(1) (2010) 21-8.

18. I. Böhm, K. Nairz, J.N. Morelli, P.S. Keller, J.T. Heverhagen, lodinated Contrast Media and the Alleged "lodine Allergy": An Inexact Diagnosis Leading to Inferior Radiologic Management and Adverse Drug Reactions, RoFo : Fortschritte auf dem Gebiete der Rontgenstrahlen und der Nuklearmedizin 189(4) (2017) 326-332.

19. European Society of Urogenital Radiology. ESUR Guidelines on Contrast Agents. Version 10.0. 2018. Available at: http://www.esur.org/fileadmin/content/2019/ESUR_Guidelines_10.0_Final_Version.pdf.

20. X. Li, H. Liu, L. Zhao, J. Liu, L. Cai, L. Zhang, L. Liu, W. Zhang, The effect of preparative solid food status on the occurrence of nausea, vomiting and aspiration symptoms in enhanced CT examination: prospective observational study, The British journal of radiology 91(1090) (2018) 20180198.

21. A. Rusandu, B.H. Sjøvold, E. Hofstad, R.J. Reidunsdatter, lodinated contrast media and their effect on thyroid function - Routines and practices among diagnostic imaging departments in Norway, Journal of medical radiation sciences 67(2) (2020) 111-118.

22. F. Amiri, M.R. Tohidnia, S. Haydarizadi, R. Azmoonfar, Contrast Agents and Observing Patient Safety Programs in Radiology Departments in Kermanshah Province Hospitals in West of Iran, Acta informatica medica : AIM : journal of the Society for Medical Informatics of Bosnia \& Herzegovina : casopis Drustva za medicinsku informatiku BiH 26(1) (2018) 42-45.

23. X. Li, J. Chen, L. Zhang, H. Liu, S. Wang, X. Chen, J. Fang, S. Wang, W. Zhang, Clinical observation of the adverse drug reactions caused by non-ionic iodinated contrast media: results from 109,255 cases who underwent enhanced CT examination in Chongqing, China, The British journal of radiology 88(1047) (2015) 20140491.

24. M.T. Costantino, L. Romanini, F. Gaeta, F. Stacul, R.L. Valluzzi, M. Passamonti, P. Bonadonna, G. Cerri, S. Pucci, P. Ricci, E. Savi, M. Galluzzo, M. Mauro, E. Grassedonio, M.R. Yacoub, A. Reginelli, S. Testi, E. Ridolo, E. Nettis, E. Di Leo, O. Rossi, P. Montuschi, C. Incorvaia, A. Romano, SIRM-SIAAIC consensus, an Italian document on management of patients at risk of hypersensitivity reactions to contrast media, Clinical and molecular allergy : CMA 18 (2020) 13.

25. S. Park, Y. In, G.Y. Suh, K. Sohn, E. Kim, Evaluation of adverse drug reactions in medical intensive care units, European Journal of Clinical Pharmacology 69(1) (2013) 119-131. 
26. S. Abe, H. Fukuda, K. Tobe, K. Ibukuro, Protective effect against repeat adverse reactions to iodinated contrast medium: Premedication vs. changing the contrast medium, European radiology 26(7) (2016) 2148-54.

27. S.Y. Lee, M.S. Yang, Y.H. Choi, C.M. Park, H.W. Park, S.H. Cho, H.R. Kang, Stratified premedication strategy for the prevention of contrast media hypersensitivity in high-risk patients, Annals of allergy, asthma \& immunology : official publication of the American College of Allergy, Asthma, \& Immunology 118(3) (2017) 339-344.e1.

28. H.J. Park, J.H. Son, T.B. Kim, M.K. Kang, K. Han, E.H. Kim, A.Y. Kim, S.H. Park, Relationship between Lower Dose and Injection Speed of lodinated Contrast Material for CT and Acute Hypersensitivity Reactions: An Observational Study, Radiology 293(3) (2019) 565-572.

29. I.B. Böhm, Lower dose and lower injection speed of iodinated contrast media: a new strategy to reduce the incidence rate of immediate hypersensitivity reactions, Quantitative imaging in medicine and surgery 10(4) (2020) 883-885.

30. I.B. Böhm, A.J. van der Molen, Recommendations for Standardized Documentation of Contrast Medium-Induced Hypersensitivity, Journal of the American College of Radiology : JACR 17(8) (2020) 1027-1028.

\section{Figures}

$1471(1.203 \%)$ cases were Excluded:

(i) Patients with incomplete form data filling $(\mathrm{N}=486)$

(ii) Unconscious patients with unavailable assessment $(\mathrm{N}=386$ )

(iii) Emergency patients with unknown medical history $(\mathrm{N}=599)$

\begin{tabular}{|c|}
\hline $\begin{array}{l}\text { Adopt conventional risk } \\
\text { assessment form }\end{array}$ \\
\hline $\begin{array}{l}\text { Parallel assessment } \\
\text { No risk stratification }\end{array}$ \\
\hline $\begin{array}{l}\text { Conduct risk assessment } \\
\text { just before examination }\end{array}$ \\
\hline $\begin{array}{l}\text { Simple questionnaires } \\
\text { on-site }\end{array}$ \\
\hline $\begin{array}{c}\text { Determine the risk to } \\
\text { benefit ratio }\end{array}$ \\
\hline $\begin{array}{l}\text { Routine anti-allergy } \\
\text { and hydration }\end{array}$ \\
\hline $\begin{array}{l}\text { Perform, delay, or } \\
\text { abandon examination }\end{array}$ \\
\hline
\end{tabular}

Conventional assessment group

All participants 122293 cases underwent enhanced CT examination between January 2014 and March 2016
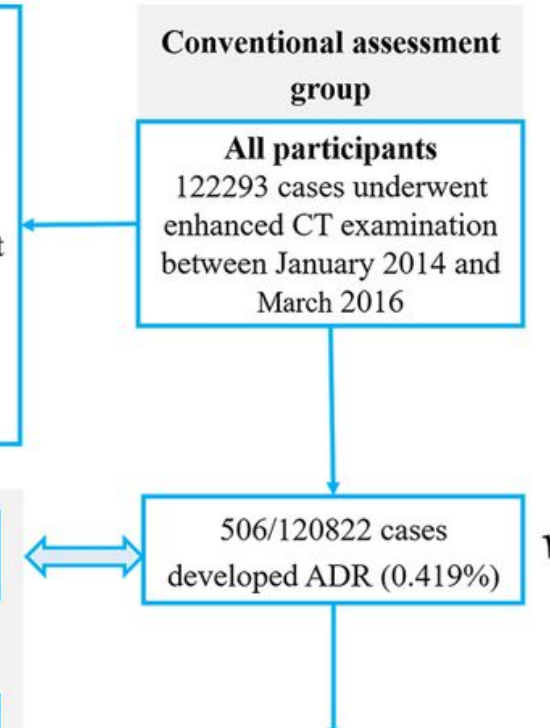

$v S$.

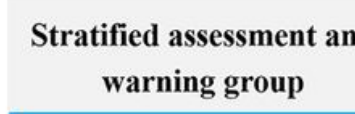

All participants

151144 cases underwent enhanced CT examination

between April 2017 and December 2019

\footnotetext{
Chi-square test for comparisons of the ADR incidence:

$>$ Patients with ADR of different severities

$>$ Patients with different risk levels

$>$ Patients with different single risk factors

$>$ Patients with different ICM types, injection doses and speeds
}

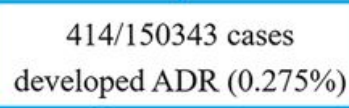

$\operatorname{ADR}(0.275 \%)$

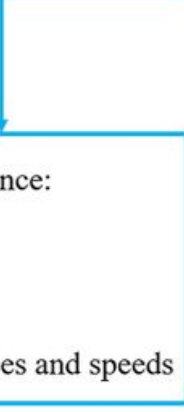

Design stratified risk assessment form

Risk stratification High, low, no risk

Conduct risk assessment as early as possible post appointment

ADR record cards Risk warning label

Clinical communication and cooperation

Full predictive process Appropriate intervention

Perform personalized examination programs 
Figure 1

Study flow diagram.
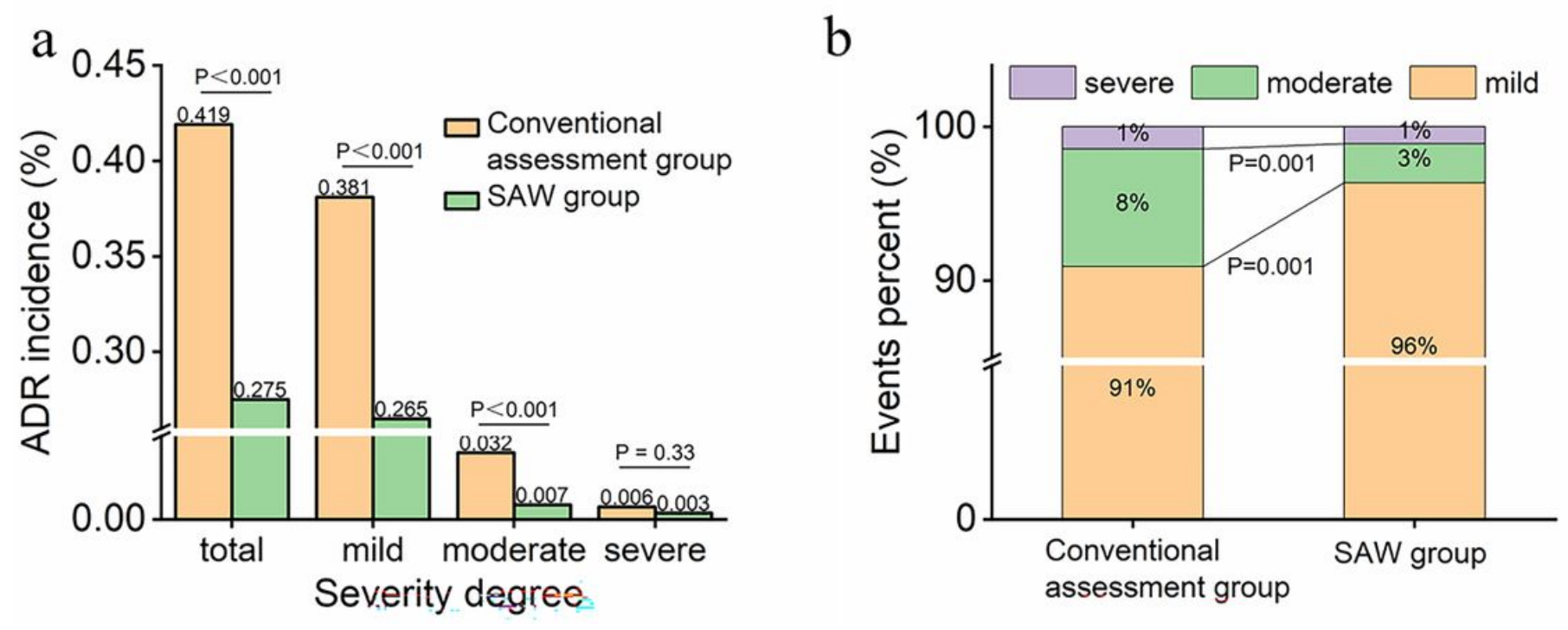

\section{Figure 2}

Comparison of the incidence and proportions of ADR with different severities in the conventional assessment group and SAW group.

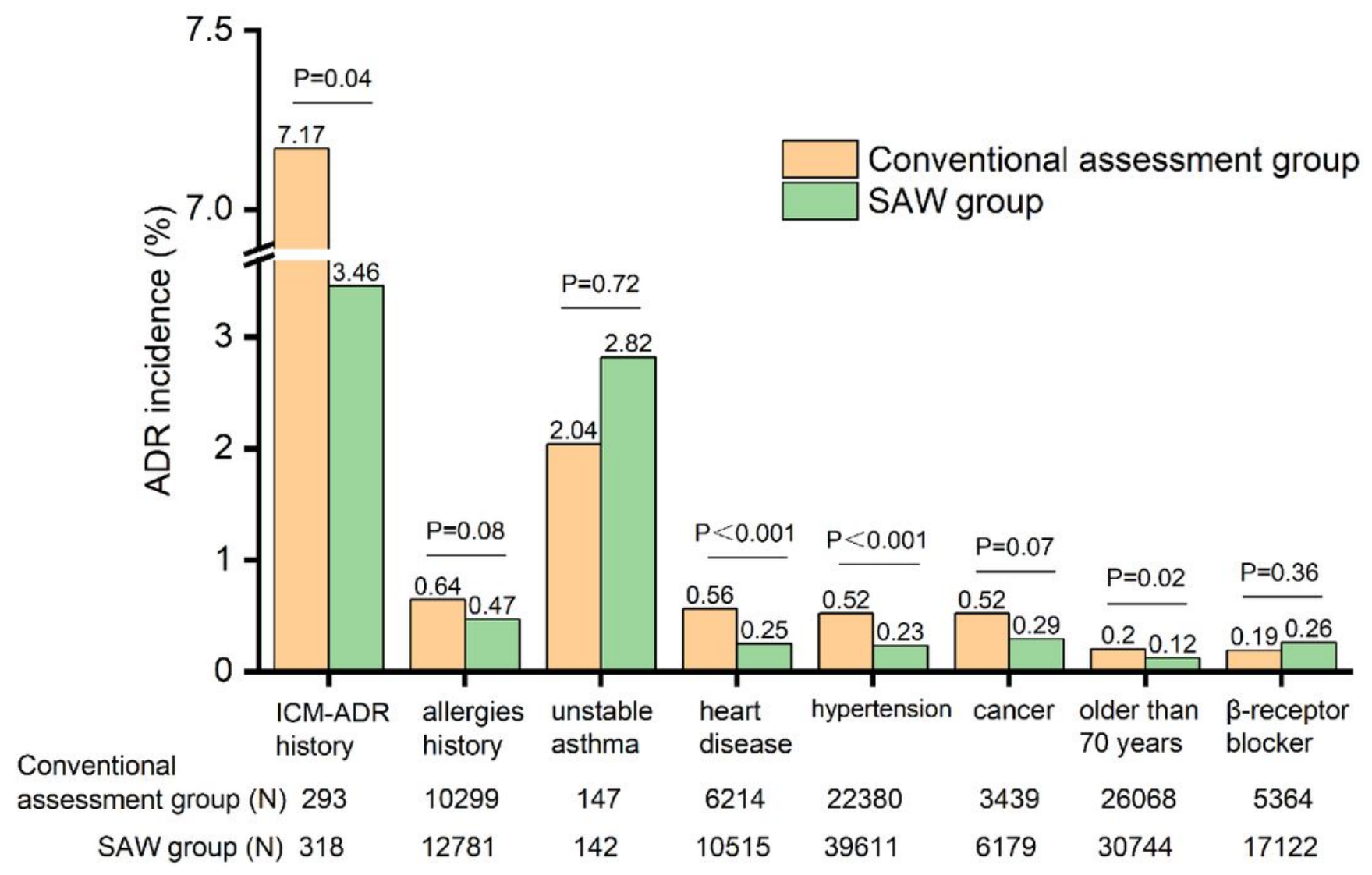


Figure 3

Comparison of the ADR incidence in patients with different single risk factors in the conventional assessment group and SAW group.

\section{Supplementary Files}

This is a list of supplementary files associated with this preprint. Click to download.

- SupplementalMaterial.docx 